\title{
Cuerpos diversos, Tetas Diversas. Acción artística para sensibilizar en igualdad de género y diversidad sexual a través de la cerámica ${ }^{1}$
}

1 Forma parte del proyecto I+D "Sensibilización en igualdad de género y diversidad sexual mediante intervenciones artísticas en contextos universitarios" que ha recibido financiación de GVA Conselleria de Innovación, Universidades, Ciencia y Sociedad Digital (Referencia: GV/2020/069).

Corpos diversos, Mamas Diversas. Ação artística para sensibilizar em igualdade de gênero e diversidade sexual através da cerâmica

Diverse bodies, Diverse Tits. Artistic action to raise awareness of gender equality and sexual diversity through ceramics

\section{Amparo Alonso Sanz ${ }^{1}$ Ricard Ramon ${ }^{2}$}

1 M.Amparo.Alonso@uv.es Universitat de València. Profesora titular del Dpto. de Didáctica de la Expresión Musical, Plástica y Corporal e investigadora del Instituto Universitario de Creatividad e Innovaciones Educativas de la Universitat de València. ORCID: https://orcid.org/0000-0002-1965-8203

2 Ricard.Ramon@valencia.edu Universitat de València. Profesor contratado doctor del Dpto. de Didáctica de la Expresión Musical, Plástica y Corporal e investigador del Instituto Universitario de Creatividad e Innovaciones Educativas de la Universitat de València. ORCID: https://orcid.org/0000-0003-1009-2589 


\section{Resumen}

En este fotoensayo, presentamos el desarrollo de la acción Tetas Diversas, realizada durante el mes de octubre de 2020 con alumnado del Grado de Maestro/a en Educación Primaria de la Facultad de Magisterio de la Universitat de València. Esta acción forma parte de un proceso de investigación para analizar y valorar el papel de las acciones artísticas en los procesos de sensibilización respecto a cuestiones de identidad de género y diversidad sexual. La experiencia consiste en la reflexión sobre la diversidad de nuestros cuerpos desde una mirada ecofeminista para reivindicar la necesidad de una institución más humanizada, naturalizada, igualitaria, respetuosa con la diversidad e inclusiva. Esta reflexión encarnada emplea el modelado de macetas de barro antropomorfas inspiradas en los trabajos de la artista Emma Low como forma de enfrentarnos a las experiencias personales de nuestro cuerpo. Los resultados consisten en múltiples acciones de sensibilización a través de la entrega de micro relatos que acompañan a estos objetos a personal docente e investigador o de administración y servicios de la Universidad.

\section{Palavras-Chave}

ecofeminismo; afectos; investigación basada en las artes; universidad; artivismo

\section{Resumo}

Neste ensaio fotográfico, apresentamos o desenvolvimento da ação Mamas Diversas, realizada durante o mês de outubro de 2020 com alunos do Mestrado em Educação Básica da Faculdade de Ensino da Universidade de Valencia. Esta ação faz parte de um processo de pesquisa para analisar e avaliar o papel das ações artísticas nos processos de sensibilização sobre as questões da identidade de gênero e diversidade sexual. A experiência consiste em refletir sobre a diversidade de nossos corpos a partir de uma perspetiva eco feminista para reivindicar a necessidade de uma instituição mais humanizada, naturalizada, igualitária, respeitadora da diversidade e inclusiva. Esta reflexão encarnada usa a modelagem de potes de barro antropomórficos inspirados nas obras da artista Emma Low como forma de confrontar as experiências pessoais do nosso corpo. Os resultados consistem em múltiplas ações de sensibilização através da entrega de micro-histórias que acompanham estes objetos ao corpo docente e investigador ou à administração e serviços da Universidade.

\section{Palavras chave}

eco feminismo; afetos; pesquisa baseada em artes; Faculdade; artivismo.

\section{Abstract}

In this photo essay, we present the development of an artistic action called Diverse Tits. It was carried out during the month of October 2020 with students of the Degree in Primary Education from the Faculty of Teaching at the University of Valencia. This action is part of a research process to analyse and assess the role of artistic actions in awareness-raising processes regarding issues of gender identity and sexual diversity. The experience consists of reflecting on the diversity of our bodies, from an ecofeminist perspective, to vindicate the need of a more humanized, naturalized, egalitarian, respectful of diversity and inclusive institution. This embodied reflection uses the modelling of anthropomorphic clay pots inspired by the artworks of Emma Low as a way to confront the personal experiences of our body. The results consist of multiple awareness actions through the delivery of micro-stories that accompany these objects. Presents to teaching, research administration and services staff of the University.

\section{Keywords}

ecofeminism; affections; arts-based research; campus; artivism.

ISSN: 2447-1267 


\section{Revista Apotheke}

El artivismo como un nuevo lenguaje que surge del desborde de la creación artística académica y museistica, hacia los espacios y lugares sociales. El artivismo, hibridación del arte y del activismo, tiene un mecanismo semántico en el que se utiliza el arte como via para comunicar una energia hacia el cambio y la transformación. (Aladro-Vico, Jivkova-Semova y Bailey, 2018, p. 9)
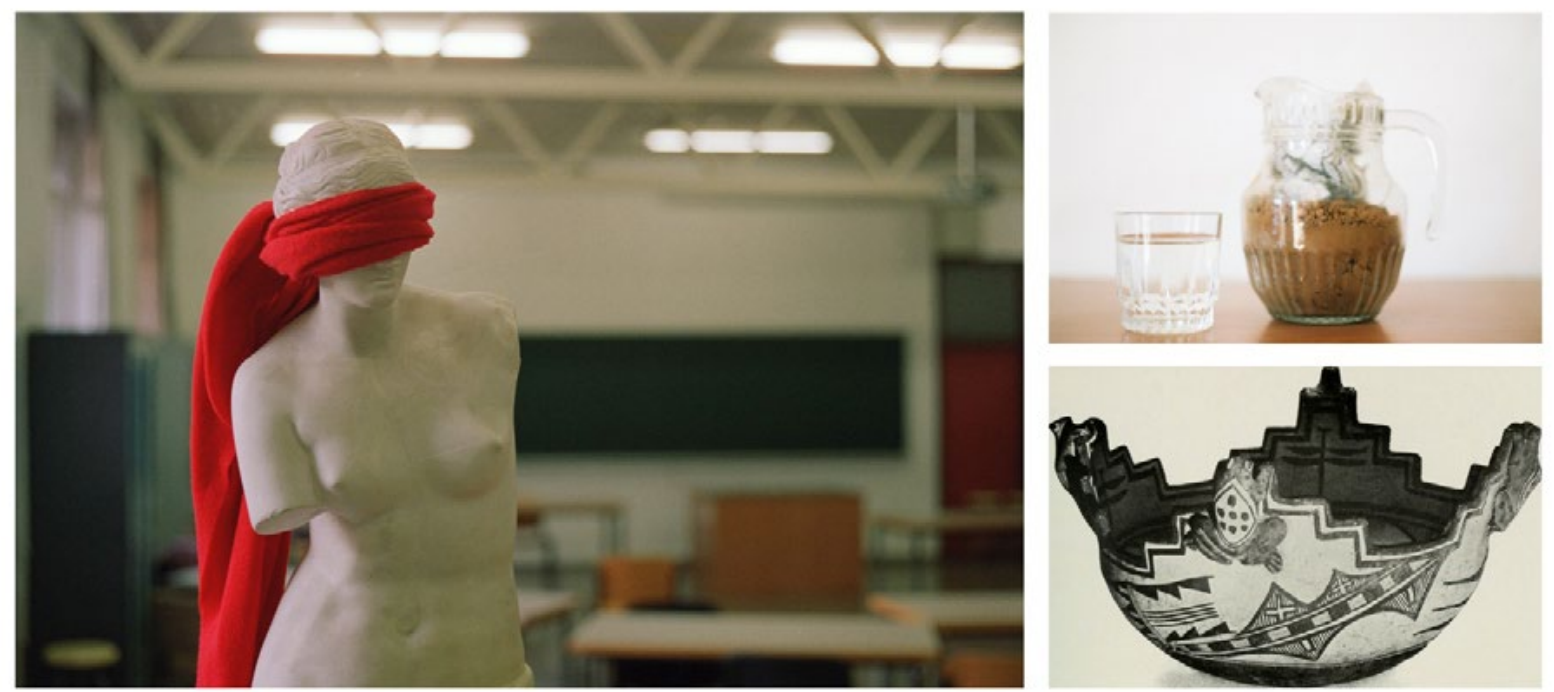

Dos fotografías independientes (autores); cita visual literal (c1900) ${ }^{1}$ y cita textual. 

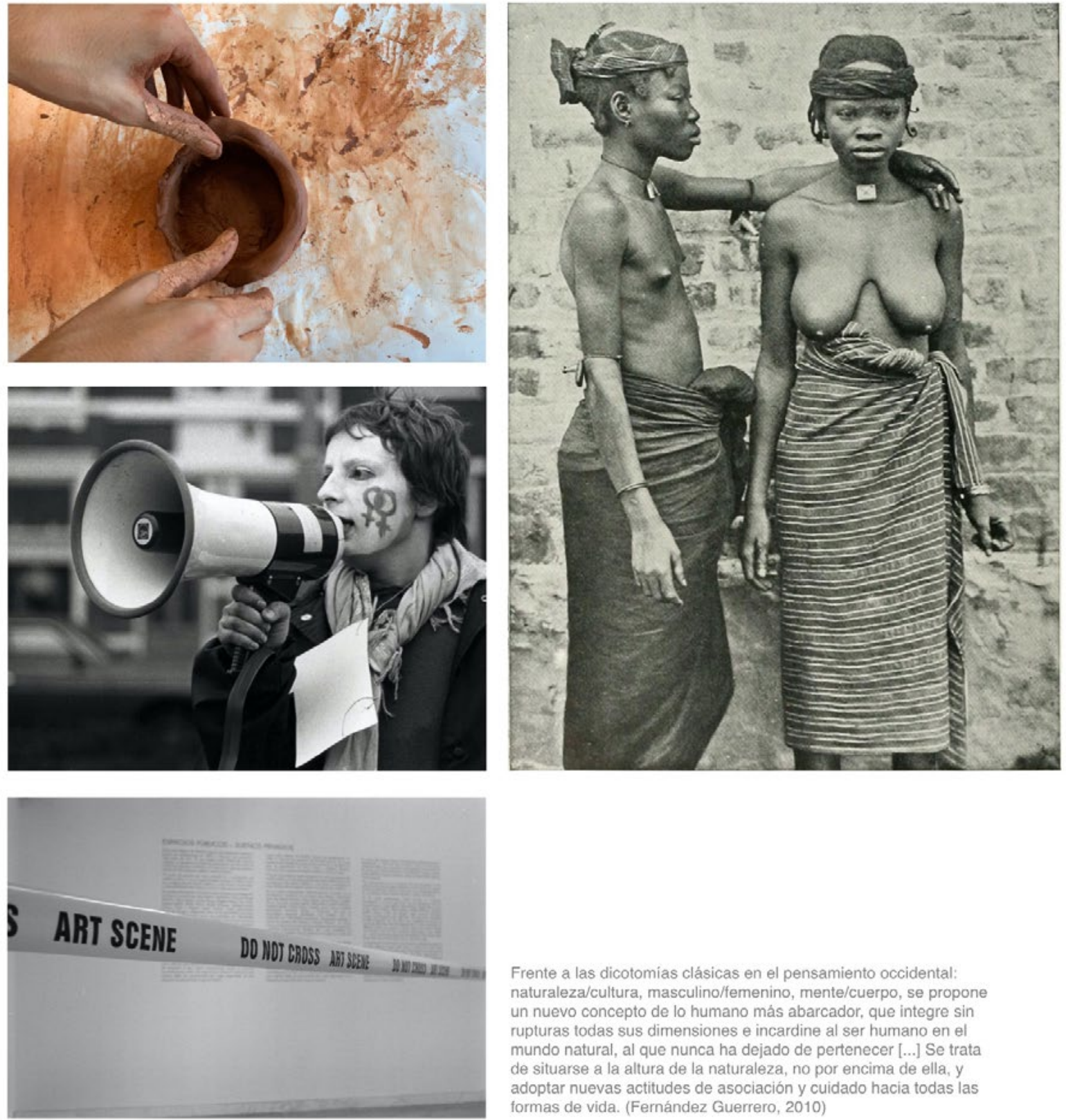

Frente a las dicotomias clásicas en el pensamiento occidental: naturaleza/cultura, masculino/femenino, mente/cuerpo, se propone un nuevo concepto de lo humano más abarcador, que integre sin rupturas todas sus dimensiones e incardine al ser humano en el mundo natural, al que nunca ha dejado de pertenecer [...] Se trata de situarse a la altura de la naturaleza, no por encima de ella, y adoptar nuevas actitudes de asociación y cuidado hacia todas las formas de vida. (Fernández Guerrero, 2010)

Fotografía independiente octubre 2020 (autores); cita visual literal (1981)2 fotografía independiente (autores), cita visual literal (Joyce, Thomas Athol, Thomas, Northcote Whitridge,1908) ${ }^{3}$ y cita textual. 

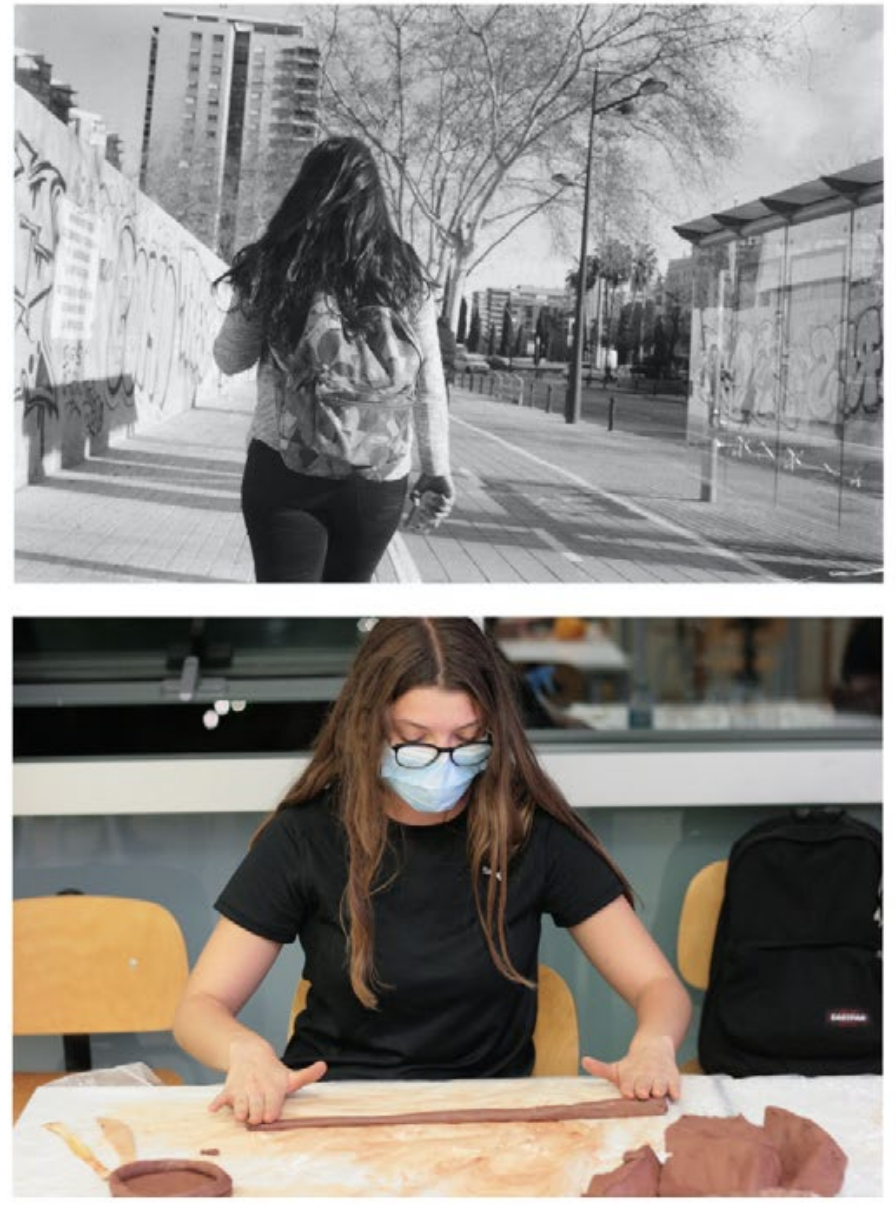

La obra de arte,en tanto que materialidad semiótica potencial (actividad de artista), o efectiva (actividad de recepción), aparece como un espacio de realización para los sujetos, no un espacio de pasividad sino un espacio de actividad en el que objetos y artefactos culturales son activados por los sujetos en el seno de la propia experiencia. [...]

Es a través de la actividad y de la generación de experiencias como los procesos de internalización constituyen procesos de apropiación y transformación. El arte, asi, es considerado menos como un objeto -según una concepción substancialista propia de la modernidad- y más como una práctica social, que incluye al conjunto de agentes sociales que, a través de sus acciones, aseguran su existencia y sus significados. (Rickenmann, 2008 , p. 181)
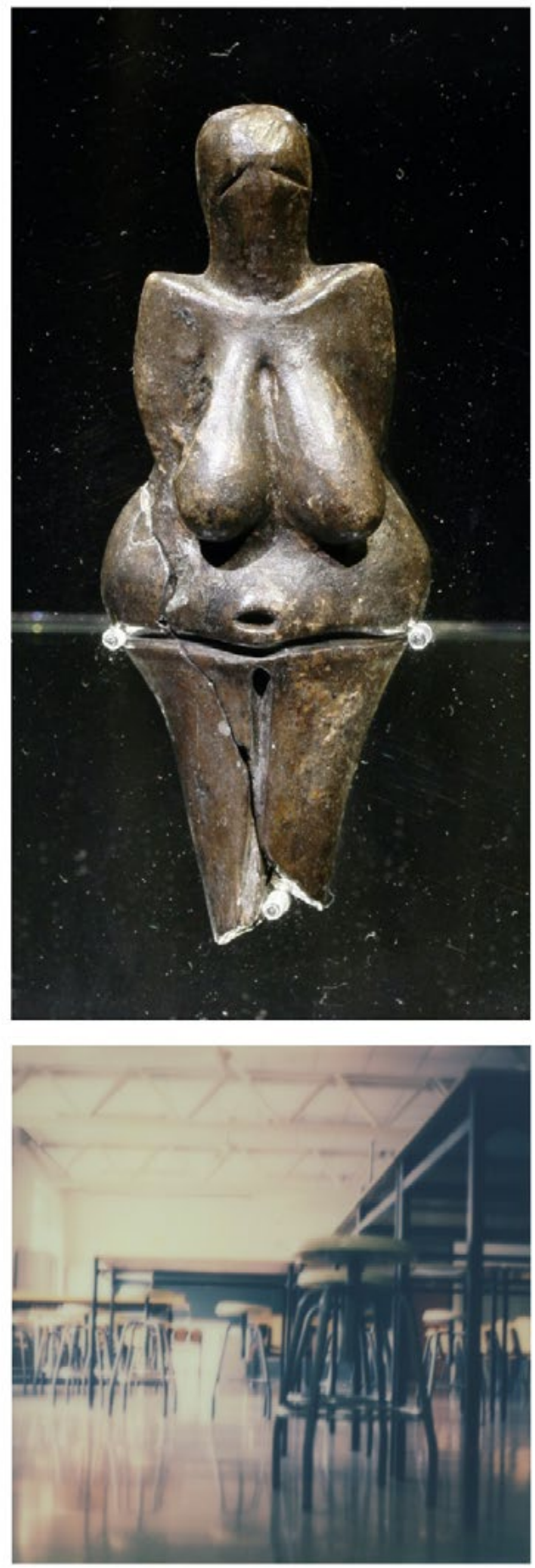

Foto ensayo compuesto por: una serie secuencia de dos fotografías (autores); cita visual literal (Petr Novák, 2007) fotografía independiente (autores) y cita textual. 

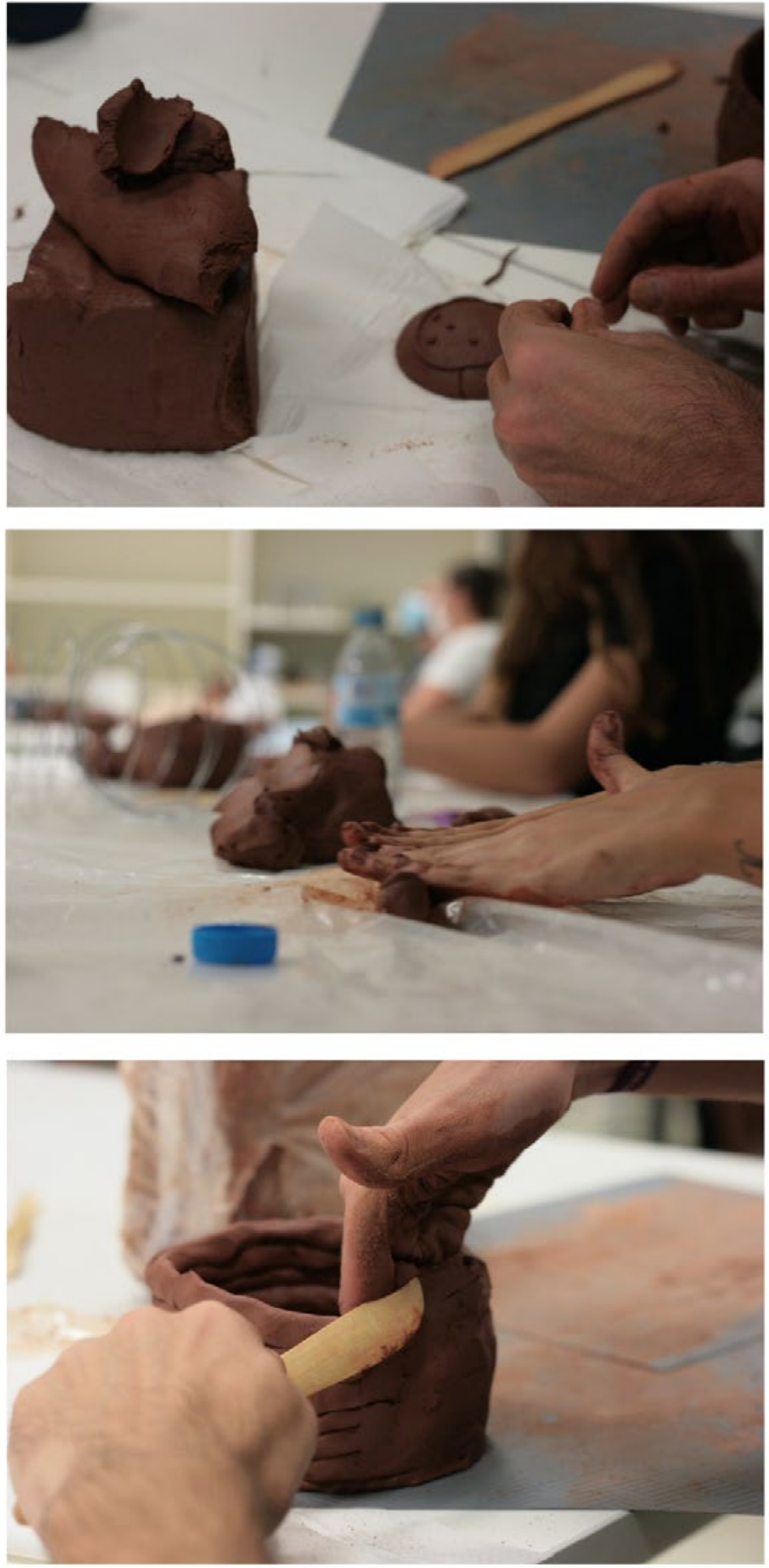
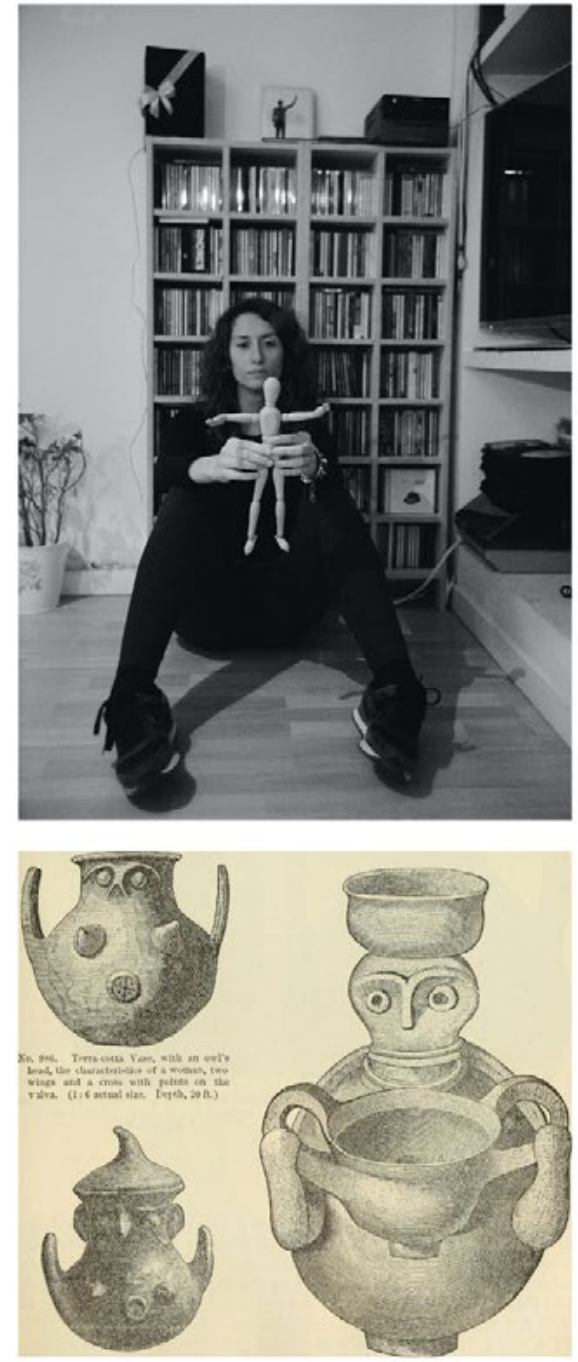

Uno a uno, los objetos producidos se van desmaterializando,se convierten en sistemas que interactúan con quien los utiliza no sólo en el plano tísico y mecánico, sino también desde un punto de vista cognitivo. (Francalaci, 2010, p. 26)

Foto ensayo compuesto por: una serie secuencia de tres fotografías tomadas en octubre de 2020 (autores); fotografía independiente (autores); cita visual literal (Schliemann, Heinrich, Virchow, Rudolf, Müller, F. Max, Sayce, A. H., Mahaffy, J. P., Brugsch, Heinrich, Ascherson, Paul, Postolakas, Achilles Burnouf, Emile, Calvert, Frank Dufield, Alexander James, 1880) ${ }^{5}$ y cita textual. 

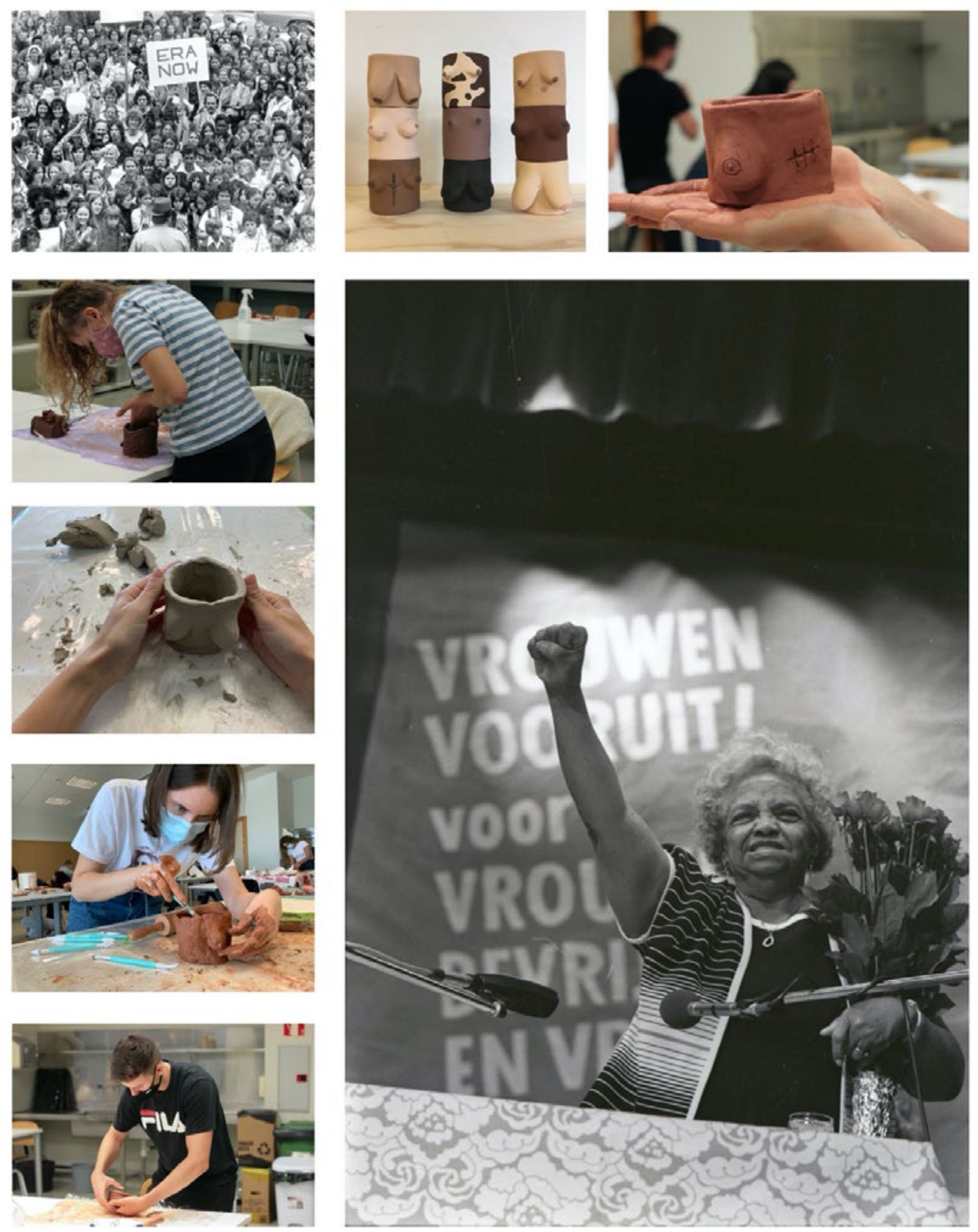

Una de las técnicas que se ha constatado más efectiva y apropiada para trabajar temas relacionados con la sexualidad ha sido el modelado en barro. Tanto el trabaio inicial de amasar, como en el de ir retocando y concluyendo, se impone un ritmo personal. El contacto con la materia es tan directo $y$ natural que provoca al tiempo una sensación de estar haciendo algo individual y a la vez colectivo, por lo antiguo, por lo ancestral. En el trabajo con arcilla se ponen en marcha el tacto, el olfato y la vista, y todos estos sentidos actuando conjuntamente remiten a otra sensación que nos enfrenta a algo dúctil y maleable, húmedo, casi vivo. Es quizás por esto que permite a las mujeres ponerse en contacto con esas vivencias tan fisicas, tan elementales, y a la vez tan profundas, dándoles un magnifico cauce de expresión a su frustración, a su dolor, desbloqueando fantasmas, recuerdos y anhelos reprimidos. (Pereira, 2009, p.32)

Cita visual literal (1979)6 , cita visual literal7 , fotografía independiente (autores), serie muestra de 4 fotografías (autores), cita visual literal (1981) y cita textual. 


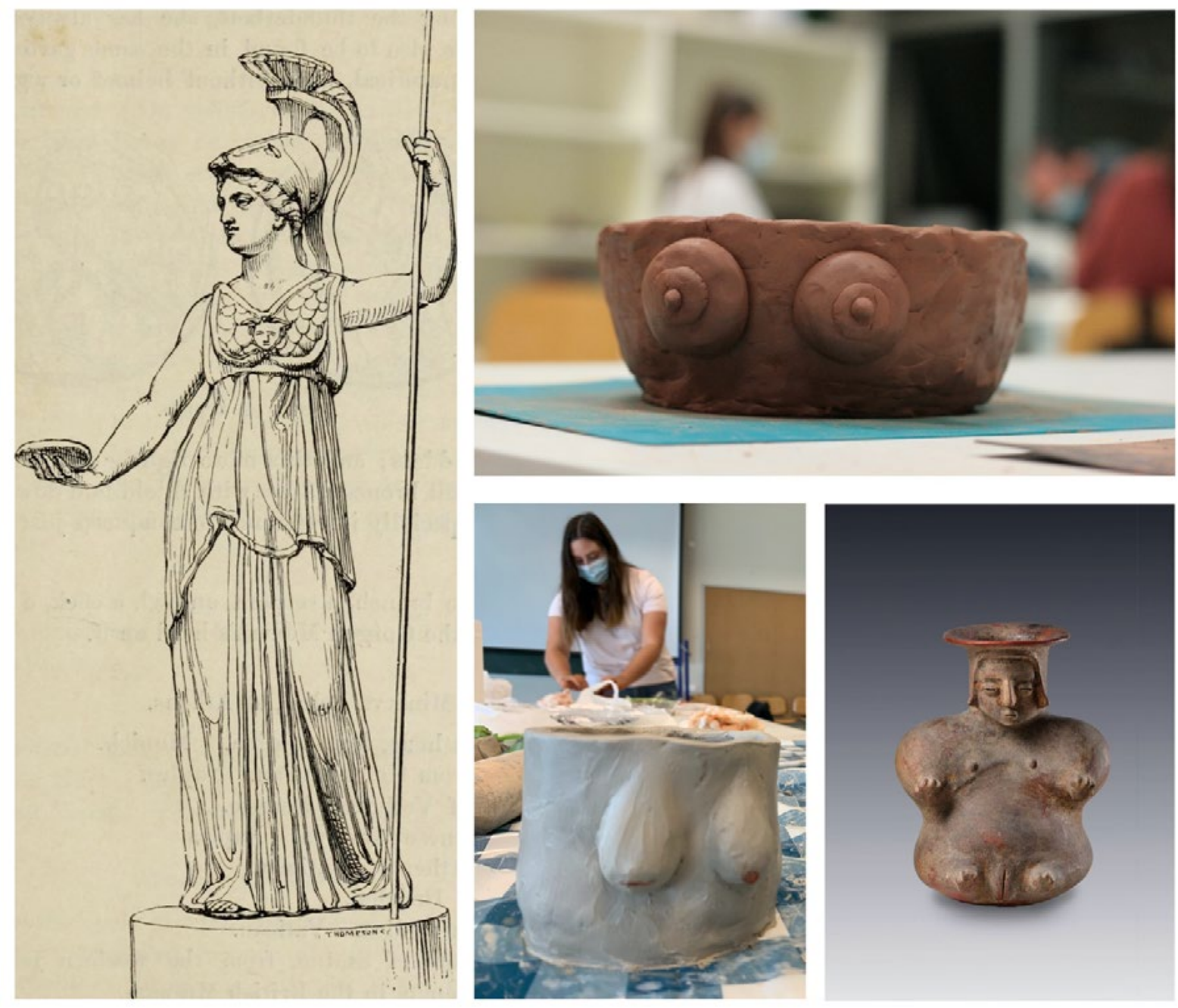

Los utensilios domésticos útiles de la casa, mantos, esteras, jarros, platos, arcos, lanzas, eran decorados con tanto cuidado que ahora vamos en su búsqueda y les damos un lugar de honor en nuestros museos. Sin embargo, en su propio tiempo y lugar, tales cosas eran medios para exaltar los procesos de la vida cotidiana. En vez de colocarse en nichos separados, pertenecian al despliegue de proezas, a la manifestación de solidaridad del grupo o del clan, al culto de los dioses, a fiestas y ayunos, a la lucha, a la caza y a todas las crisis ritmicas que puntuaban la corriente del vivir. (Dewey, 2008$, p. 7$)$

Cita visual literal (Westropp, Hodder M. 1867) ${ }^{9}$, serie muestra de dos fotografías tomadas en octubre de 2020 (autores), cita visual literal ${ }^{10}$ y cita textual. 

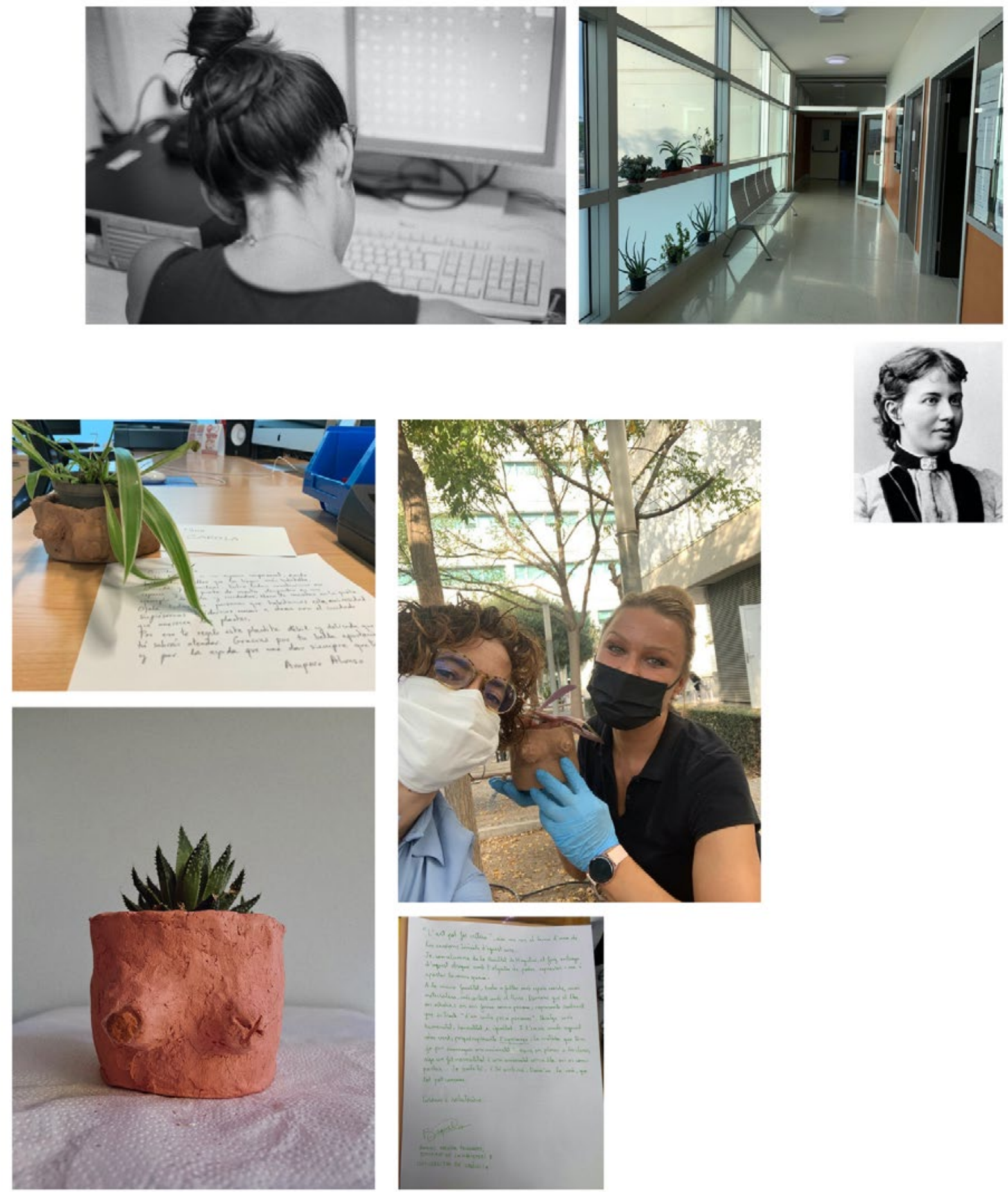

Pero el afecto no es una fuerza que esté aislada, sino que es transversal, ya que cruza todas las dimensiones del conocimiento, del sujeto y de la realidad. Además, implica un cambio sustancial en las relaciones en torno a la política, la investigación y la pedagogia. (De Riba Mayoral, Hernández y Revelles, 2020, p. 234)

Fotoensayo compuesto por dos fotografías (autores), cita visual literal (1880) ${ }^{11}$ serie muestra de cuatro fotografías (dos primeras: autores; dos últimas: Raquel Hermida) y cita textual. 


\section{Referencias}

ALADRO-VICO, Eva., JIVKOVA-SEMOVA, Dimitrina., y BAILEY, Olga. Artivismo: Un nuevo lenguaje educativo para la acción social transformadora. Comunicar, 57, 9-18. 2018.

DE RIBA MAYORAL, Silvia, HERNÁNDEZ HERNÁNDEZ, Fernando, y REVELLES BENAVENTE, Beatriz. Aportaciones para la formación del profesorado y una pedagogía de los afectos. En HERNÁNDEZ, Fernando, ABERASTURI APRAIZ, Estíbaliz, SANCHO GIL, Juana María y CORREA GOROSPE, José Miguel (Eds.), ¿Cómo aprenden los docentes?: Tránsitos entre cartografías, experiencias, corporeidades y afectos. Barcelona: Octaedro. Edición de Kindle. 2020. p. 232-253

DEWEY, John. El arte como experiencia. Barcelona: Paidós. 2008.

FERNÁNDEZ GUERRERO, Olaya. Cuerpo, espacio y libertad en el ecofeminismo. Nómadas. Revista Crítica de Ciencias Sociales y Jurídicas, 27(3). 2010.

FRANCALANCl, Ernesto. L. Estética de los objetos. Madrid: Antonio Machado Libros. 2010. HUERTA, Ricard. Transeducar. Arte, docencia y derechos LGTB. Madrid-Barcelona: Egales. 2016.

PEREIRA, T. El cuerpo enclaustrado. Arteterapia, 31(4), 27-42. 2009-

RICKENMANN, René. Arte, patrimonio y experiencia estética. Hacia una reconcepción de las enseñanzas artísticas basada en el análisis de la mediación docente. En AGUIRRE, Imanol (Ed.), El acceso al patrimonio cultural. Retos y debates. Pamplona: Universidad Pública de Navarra. 2008. p. 165-183. 